\title{
THERMAL CONDUCTIVITY ENHANCEMENT OF AQUEOUS IONIC LIQUID AND NANOPARTICLE SUSPENSION
}

\author{
Divya P. Soman ${ }^{1}$, P. Kalaichelvi ${ }^{1 *}$ and T. K. Radhakrishnan ${ }^{1}$ \\ ${ }^{1}$ National Institute of Technology, Department of Chemical Engineering, Tiruchirappalli, Tamil Nadu, India. \\ ORCID: 0000-0001-5850-7849; E-mail: kalai@nitt.edu - ORCID: 0000-0001-7396-3500; ORCID: 0000-0002-7208-5993 \\ (Submitted: September 15, 2018 ; Revised: November 13, 2018 ; Accepted: February 17, 2019)
}

\begin{abstract}
In the present study, the thermal conductivities of ionic liquid + water in the concentrations 0.1$0.6 \% \mathrm{w} / \mathrm{w}$ and temperatures $(302.5-337.9 \mathrm{~K})$ are determined. The thermal conductivity of aqueous 1-butyl3 -methylimidazolium bromide declined with increasing concentration and temperature. A quadratic model is developed for predicting the thermal conductivity of aqueous ionic liquid using response surface methodology with $\mathrm{R}^{2}=0.99$. A two-layered feed forward back propagation neural network 2-10-1 is also modeled with mean square error, root means square and absolute average error percentage of $0.005,0.071$ and 2.684, respectively. The thermal conductivity of nanofluid $\left(\gamma-\mathrm{Al}_{2} \mathrm{O}_{3} /\right.$ water $)$ is estimated and compared with the ionic liquid solution at the same concentration and temperature range. Thermal conductivity enhancement ratios of aqueous ionic liquids are found to be more than nanoparticle suspensions.

Keywords: Thermal conductivity; Ionic liquid; Response surface methodology; Artificial neural network; Nanofluid.
\end{abstract}

\section{INTRODUCTION}

Ionic liquids have recently received considerable attention for their wide range of applications, which are inevitably possible due to the attractive chemical and physical properties of these chemicals (Amarasekara and Owereh, 2011). The ionic liquids are mainly used as catalysts, solvents, electrolytes, biosensors, heat transfer fluids, reaction media, thermal stabilizers and polymeric plasticizers (Chernikova et al., 2015; Hamidova et al., 2015; Sathyabhama and Hegde, 2006; Soman et al., 2016). Ionic liquids are entirely composed of organic cations with different alkyl substituents or functional groups and inorganic anions. They are organic salts with a boiling point below $100^{\circ} \mathrm{C}$ (Ghandi, 2014; Hamidova et al., 2015; Soman et al., 2016). The thermophysical properties of the ionic liquids are entirely dependent on the ions with which they are composed (Ghandi, 2014). A most interesting characteristic feature of ionic liquids is the potentiality of tuning their properties for a given task (Santos et al., 2015). This can be obtained by adjusting the chemical structure of the constituent ions. Some of the exceptional properties of ionic liquids are low vapor pressure, remarkable catalytic properties, high ionic conductivity, high thermal stability, nonflammability and excellent solubility with organic and inorganic compounds (Santos et al., 2015; Soman et al., 2016).

Nanofluids are a class of engineered fluids made of metallic particles of average size less than $100 \mathrm{~nm}$ suspended in a base fluid (Aybar et al., 2015). The base fluid may be industrial heat transfer fluids such as water, engine oil, ethylene glycol etc. The nanofluids are expected to exhibit superior properties compared to fluids that contain micrometer-sized particles and other conventional heat transfer fluids. The reason is that heat transfer takes place at the surface of the particle, so it is suitable to use particles with higher surface area. Nanoparticles have larger surface area and so have greater potential in a variety of applications

\footnotetext{
* Corresponding author: P. Kalaichelvi - E-mail: kalai@nitt.edu
} 
such as photocatalysts (Ma et al., 2017), mass transfer processes like the removal of $\mathrm{H}_{2} \mathrm{~S}$ (Ma and Zou, 2018) and heat transfer applications (Kumar and Chakrabarti, 2014). The thermophysical properties have to be assessed for their specific applications in heat transfer studies (Li et al., 2018, 2017; Li and Zou, 2018a). The large surface area of the nanopowder markedly improves the heat transfer capability and stability of the suspensions (Choi and Eastman, 1995).

High thermal conductivity metallic nanoparticles (copper, aluminium, silicon) enhance the thermal conductivity of the nanofluid. In most of the studies, metallic oxides of the nanoparticles are used by researchers. Metal oxides of nanoparticles have been broadly utilized as a part of numerous applications, for example in medical science, sensors, semiconductors, catalysis, batteries and capacitors (Kumar and Chakrabarti, 2014). As can be seen from the literature, extensive research has been carried out with alumina $\left(\mathrm{Al}_{2} \mathrm{O}_{3}\right)$ /water systems. The main reason for this is due to the very interesting properties of $\mathrm{Al}_{2} \mathrm{O}_{3}$ such as high hardness, high stability, high insulation and transparency (Piriyawong et al., 2012). It is a white oxide which exists in several phases like alpha, gamma, delta, and theta. Alpha is the most thermodynamically stable phase (Piriyawong et al., 2012). However, the gamma phase possesses a higher specific surface area equal to $200 \mathrm{~m}^{2} \mathrm{~g}^{-1}$ which is very advantageous especially for heat transfer applications (Vasheghani et al., 2011). Vasheghani et al. (2011) studied the effect of thermal conductivity enhancement of engine oils with gamma $\mathrm{Al}_{2} \mathrm{O}_{3}\left(\gamma-\mathrm{Al}_{2} \mathrm{O}_{3}\right)$ and alpha $\mathrm{Al}_{2} \mathrm{O}_{3}\left(\alpha-\mathrm{Al}_{2} \mathrm{O}_{3}\right)$. They concluded that, by addition of $3 \% \mathrm{w} / \mathrm{w}$ of $\gamma-\mathrm{Al}_{2} \mathrm{O}_{3}$ and $\alpha-\mathrm{Al}_{2} \mathrm{O}_{3}$ to engine oil the thermal conductivity was enhanced by $37 \%$ and $31 \%$, respectively. Lee and Mudawar (2007) performed experiments with $1 \%$ and $2 \%$ volume concentrations of $\mathrm{Al}_{2} \mathrm{O}_{3}$ /water to explore the benefits of single and two-phase heat transfer in a microchannel. The Hamilton-Crosser model was employed for the thermal conductivity calculation in their study. Heris et al. (2007) investigated laminar flow forced heat transfer with $0.2 \%, 0.5 \%, 1 \%, 1.5 \%$, $2 \%$ and $2.5 \%$ volume concentration $\mathrm{Al}_{2} \mathrm{O}_{3} /$ water inside a circular tube and the $\mathrm{Yu}$ and Choi correlation (Heris et al., 2007) was employed for calculating the thermal conductivity of the nanofluid in their study. Perarasu et al. (2013) examined heat transfer of $\mathrm{Al}_{2} \mathrm{O}_{3} /$ water nanofluid at $0.1 \%, 0.2 \%$ and $0.3 \%$ volume concentration in a coiled agitated vessel equipped with a propeller and the Maxwell equation was applied for determining the thermal conductivity of the nanofluid.

From the industrial and scientific point of view, a basic understanding of the physicochemical properties of ionic liquids and nanofluids is required before their application in several processes. Many combinations of nanofluids in ionic liquids have been used in a wide range of applications ( $\mathrm{Li}$ and Zou, 2018b). However, in the case of heat transfer applications, thermal conductivity is an essential property. Its understanding is a pre-requisite for evaluating the heat transfer coefficient, which is required for the design of heat transfer equipment and for selection of heat transfer fluid (Lazzús, 2015a). The experimental data of this property is available for only a limited number of ionic liquids. Various authors have proposed correlations and predictive models for estimation of thermal conductivity (Albert and Muller, 2014; Carrete et al., 2012; Chen et al., 2014; Hezave et al., 2012; Hosseini et al., 2016; Lazzús, 2015a, 2015b; Lazzús and PulgarVillarroel, 2015; Shojaee et al., 2013).

In this context, Albert and Muller (2014) have developed a Quantitative Structure-Property Relationship (QSPR) model for the determination of the thermal conductivity. It uses the experimental data of 39 pure ionic liquids, covering a temperature range of $273.15 \mathrm{~K}$ to $390 \mathrm{~K}$. The QSPR model is based on the information of ions constituting it as the only input parameter. Furthermore, in their method, contributions are assigned to each anion and cation, and these contributions are summed up to get the thermal conductivity. Hezave et al. (2012) have developed a perceptron neural network model for predicting the thermal conductivity. It uses 21 different pure ionic liquids with an overall absolute mean relative deviation percent of $0.5 \%$ and mean square error of $1.2 \times 10^{-}$ ${ }^{6}$. Lazzús (2015b) proposed a model, using a group contribution method, to predict thermal conductivity as a function of temperature (302.52-337.92 K) and pressure (100-20000 $\mathrm{kPa})$. This model has an average relative absolute deviation less than $1.90 \%$ for the correlation set. The experimental data of 41 pure ionic liquids were collected from literature for their studies.

In most of the reported methods, the prediction of thermal conductivities is possible for just those ionic liquids whose cations and anions fall among the functional groups selected. In addition, only limited literature is available on experimental studies of thermal conductivity of binary mixtures of ionic liquid and water. Response Surface Methodology (RSM) is a powerful tool to develop a mathematical model relating a dependent variable(s) with independent variable(s). Moreover, to the best of the author's knowledge there is no application of RSM and a feed-forward backpropagation neural network for modeling the thermal conductivity of the aqueous ionic liquid, as presented here, and certainly there is no publication on the thermal conductivity of a binary solution of 1-butyl-3methylimidazolium bromide (BMImBr) and water. As a consequence, we focus on determining the thermal conductivity of binary mixtures of $\mathrm{BMImBr}$ and water at different temperatures (302.52-337.92 K) and concentrations $(0.1-0.6 \% \mathrm{w} / \mathrm{w})$ experimentally using a 
guarded parallel plate instrument. A new mathematical model equation has been proposed using RSM to determine the thermal conductivity of $\mathrm{BMImBr}+$ water binary solution as a function of temperature and concentration. Additionally, a feed-forward backpropagation neural network has also been developed for prediction of the thermal conductivity of $\mathrm{BMImBr}$ solution and compared with the RSM. Since, $\gamma-\mathrm{Al}_{2} \mathrm{O}_{3}$ possess remarkable properties and has been effectively used as nanoparticles in heat transfer application studies, it is also used for a comparative study of the thermal conductivities of the $\mathrm{BMImBr}+$ water ionic liquid solution and the nanofluid $\left(\gamma-\mathrm{Al}_{2} \mathrm{O}_{3} /\right.$ water $)$ with water as the base fluid. The thermal conductivity of nanofluid $\left(\gamma-\mathrm{Al}_{2} \mathrm{O}_{3}\right.$ /water $)$ was calculated based on Maxwell's equation (non-experimentally derived values at the same concentration and temperature range of ionic solution were used).

\section{MATERIALS AND METHODS}

\section{Materials}

BMImBr (Molecular formula: $\mathrm{C}_{8} \mathrm{H}_{15} \mathrm{BrN}_{2}$ ) ionic liquid procured from M/s. Alfa Aesar with 99\% purity and spherical shaped 20-30 nm aluminium oxide (gamma) nanoparticle powder $\left(\gamma-\mathrm{Al}_{2} \mathrm{O}_{3}\right)$ with $99.97 \%$ purity purchased from $\mathrm{M} / \mathrm{s}$. Otto are used. The ionic liquid is in a solid state and is stored in a cool, dry place. The thermal conductivity apparatus purchased from $\mathrm{M} / \mathrm{s}$. Mass International, Haryana is used for the measurement of liquid state thermal conductivity of the chosen ionic liquid. The samples are weighed on a Shimadzu electronic weighing balance with a precision $\pm 0.001 \mathrm{~g}$. Six resistance temperature detectors-platinum thermometers (RTD-PT 100) with $0.1{ }^{\circ} \mathrm{C}$ least count were used for measuring temperature. The X-ray diffraction (XRD) technique is used for the size determination of $\gamma-\mathrm{Al}_{2} \mathrm{O}_{3}$ nanoparticles. XRD measurements are performed on an X-ray diffractometer (Ultima IV, Rigaku, Japan) operated at $40 \mathrm{kV}$ and $30 \mathrm{~mA}$, equipped with an $\mathrm{X}$-ray source emitting $\mathrm{CuK} \alpha$ radiation $(\lambda=0.15406$ $\mathrm{nm})$. The XRD patterns from $20^{\circ}$ to $80^{\circ}$ are recorded at room temperature with the following measurement conditions: scan speed of $5^{0}$ per minute and the step size of $0.05^{\circ}$.

\section{Preparation of BMImBr aqueous solution}

A sample solution of $0.5 \mathrm{~L}$ is prepared by mixing the ionic liquid with water on a weight by weight basis to obtain different concentrations ranging from $0.1-0.6$ $\% \mathrm{w} / \mathrm{w}$ and this range is selected in accordance with the conventional values used in industry. Each sample is stirred well with a magnetic stirrer to assure that ionic liquid is completely dissolved in water. The samples are tightly closed while stirring.

\section{Thermal conductivity measurements of $\mathrm{BMImBr}$ aqueous solution}

The apparatus works on the basis of the guarded hot plate method. It is a steady state absolute method used for the measurement of thermal conductivity of fluids, which can be fixed between two parallel plates. The schematic diagram of the thermal conductivity measurement apparatus for liquids is shown in Figure 1. A cold plate, hot plate, RTD PT- 100 sensors, a heater to heat the hot plate, cold water supply for the cold plate and the liquid specimen holder are the essential components of the set-up. In this set-up, a unidirectional heat flow takes place across the liquid whose two faces are maintained at different temperatures by the hot plate on one end and by the cold plate at the other end. The gap between the hot plate and cold plate forms the liquid cell, in which the liquid sample is filled. An electric heater heats the hot plate and voltage to the heater is varied with the help of a variac to conduct experiments at different voltages as well as at different heat inputs. The RTD PT-100 sensors attached at three different places on the hot plate and cold plate are used to measure the temperatures. The uncertainty in temperature measurement is $0.1 \%$.

These sensors are provided on the inner surface facing the liquid sample. An average temperature output of these sensors is recorded as $T_{h}$ and $T_{c}$ at steady state conditions. The voltmeter and ammeter readings are noted after the steady state is attained. The temperature of the cold surface is maintained by circulating cold water at 1 LPM. The depth of the liquid in the direction of heat flow is kept small to ensure the absence of convection currents and a liquid sample with high viscosity and density can ensure the absence of convection and the heat transfer is assumed to take place by conduction alone. The thermal conductivity measurement apparatus specifications are given in Table 1 . The apparatus is calibrated using glycerol as a

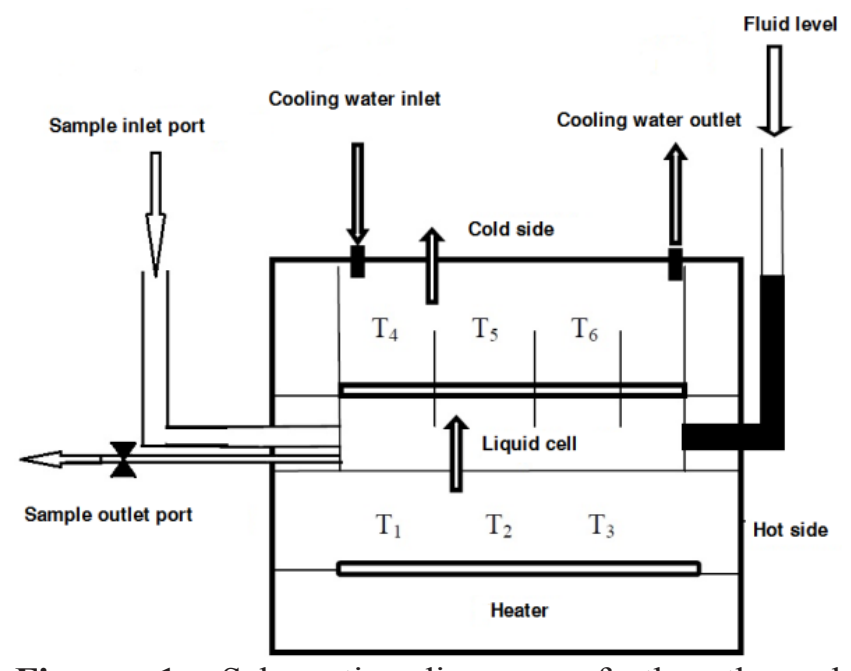

Figure 1. Schematic diagram of the thermal conductivity measurement apparatus. 
Table 1. Thermal Conductivity Measurement Apparatus Specification.

\begin{tabular}{ccc}
\hline Specification & Value \\
\hline Material & Hot Plate & Brass \\
Diameter & & $0.16 \mathrm{~m}$ \\
\hline & Cold Plate & Aluminum \\
Material & $0.16 \mathrm{~m}$ \\
Diameter & $0.018 \mathrm{~m}$ \\
Depth of the sample $(\Delta \mathrm{D})$ & RTD PT-100 \\
Temperature Sensors (Type) & 6 No's. \\
Quantity & No.1 to No.3 mounted on a hot \\
& plate \\
Location & No.4 to No.6 mounted on cold \\
& plate \\
Digital temperature indicator & 273.15 to $473.05 \mathrm{~K}$ \\
range & $273.25 \mathrm{~K}$ \\
Least Count & 2 A and 230 V - Alternating \\
Variac & Current (AC) \\
Digital voltmeter range & 0 to $250 \mathrm{~V}$ \\
Digital ammeter range & 0 to $2.5 \mathrm{~A}$ \\
Heater & Nichrome heater 250 W \\
\hline
\end{tabular}

sample fluid to test the reliability and accuracy of the thermal conductivity measurement.

The liquid cell of the apparatus is filled with the $0.1 \% \mathrm{w} / \mathrm{w}$ solution of $\mathrm{BMImBr}$ through the inlet port by closing the sample outlet port. To facilitate complete removal of air through the outlet port the liquid is filled very slowly until the sample comes out of the sample level port. The cold water is allowed to flow through the cold water inlet port. The heater is switched on for the supply of heat to the hot plate. The voltage of the hot plate heater is varied from $40-100$ $\mathrm{V}$ and the readings are recorded for every $10 \mathrm{~V}$ rise. Once the steady state is attained, three sensor readings $\left(T_{1}, T_{2}, T_{3}\right.$ i.e., $\left.T_{h l}, T_{h 2}, T_{h 3}\right)$ on the hot side and the three sensor readings $\left(T_{4}, T_{5}, T_{6}\right.$, i.e., $\left.T_{c l}, T_{c 2}, T_{c 3}\right)$ on the cold side along with the ammeter and voltmeter readings are noted and the thermal conductivity of the aqueous BMImBr is calculated using Eq.1. The same procedure is continued to collect data on temperature, voltage and current for all the other $0.2-0.6 \% \mathrm{w} / \mathrm{w}$ concentration samples of aqueous BMImBr solution.

The principle of the guarded plate method is that, when a temperature gradient exists in a body, there is an energy transfer from the high-temperature region to the low-temperature region. The mode of energy transfer is conduction and the heat transfer rate per unit area is proportional to the normal temperature gradient. At steady state, the average face temperatures are recorded $\left(T_{h}\right.$ and $\left.T_{c}\right)$ along with the rate of heat transfer. With the available data of heat transfer area and thickness of the sample, the thermal conductivity is calculated using Fourier's Law of heat conduction (Eq.1).
$\mathrm{Q}=\frac{\mathrm{kA}\left(\mathrm{T}_{\mathrm{h}}-\mathrm{T}_{\mathrm{c}}\right)}{\Delta \mathrm{X}}$

where $k$ is the thermal conductivity of the ionic liquid $\left(\mathrm{Wm}^{-1} \mathrm{~K}^{-1}\right), A$ is the area of heat transfer $\left(\mathrm{m}^{2}\right)$ calculated using Eq.2, $T_{h}$ and $T$ are the average temperatures of the recorded hot and cold plate temperatures $(\mathrm{K}), Q$ is the amount of heat transferred through the liquid at steady state (W) calculated using Eq. 3 and $\Delta X$ is the depth of the sample (m).

$\mathrm{A}=\frac{\pi \mathrm{D}^{2}}{4}$

where $D$ is the diameter of the plate (m).

$\mathrm{Q}=\mathrm{EI}$

where $E$ is the voltage (V) and $I$ is the current (A).

Response surface methodology for predicting thermal conductivity of BMImBr aqueous solution

The RSM is a collection of statistical and mathematical methods that are established for the fit of empirical models to the experimental data. Central composite design (CCD) is the most popular RSM design that has three groups of design points, namely two-level factorial or fractional factorial design points, center points and axial points (Biniaz et al., 2016). Central composite face-centered design (CCFCD) with two independent variables coded at three levels between -1 and +1 is applied to model the thermal conductivity of aqueous solutions of BMImBr. Temperature and concentration of BMImBr solution are the two independent factors opted for modeling (Table 2). Design Expert 10.0.3.3 software is used to model the equation for thermal conductivity of the fluids. The generated runs for CCFCD in this work are 13 with two factors.

The experimental data from the CCD model for thermal conductivity of the $\mathrm{BMImBr}$ ionic liquid solutions are fitted to a second order polynomial equation (Eq. 4) and the regression coefficients are obtained.

$\mathrm{Y}=\beta_{0}+\beta_{1} \mathrm{~A}+\beta_{2} \mathrm{~B}+\beta_{3} \mathrm{~A}^{2}+\beta_{4} \mathrm{~B}^{2}+\beta_{5} \mathrm{AB}+\mathrm{e}$

where $Y$ is the response variable, $A$ and $B$ are the independent variables, $\beta_{0}$ is the constant or offset term,

Table 2. Physical and coded values of independent process variables.

\begin{tabular}{cccc}
\hline \multirow{2}{*}{ Factors } & \multicolumn{3}{c}{ Levels and range } \\
\cline { 2 - 4 } & Low & Center & High \\
\hline Temperature $(\mathrm{K})$ & $303.2 \pm 0.4$ & $318.2 \pm 0.4$ & $333.2 \pm 0.4$ \\
Concentration $(\% \mathrm{w} / \mathrm{w})$ & 0.1 & 0.35 & 0.6 \\
\hline
\end{tabular}


$\beta_{1}$ and $\beta_{2}$ are the slopes or linear coefficient of the input factors, $\beta_{3}$ and $\beta_{4}$ are the quadratic coefficients, $\beta_{5}$ is the interaction coefficient and $e$ is the statistical error (Biniaz et al., 2016). Temperature $(T)$ and concentration $(C)$ are the independent variables and thermal conductivity of the aqueous ionic liquid solution $\left(k_{i o}^{p r e}\right)$ is the response variable. The response data are obtained from the test work of 13 runs. When the p-value is higher than 0.05 at the $95 \%$ confidence level, the effects are considered to be not statistically significant. The quality of fit of the quadratic model equation is expressed by the value of the correlation coefficients $\left(\mathrm{R}^{2}\right)$ and the significance is checked using the F-test (Abdullah et al., 2014). The main aim is to determine the second order polynomial equation for the thermal conductivity of aqueous solutions of the ionic liquid as functions of temperature and concentration.

\section{Artificial neural networks for predicting thermal conductivity of BMImBr aqueous solution}

The functioning of the artificial neural network (ANN) is developed from the behavior of biological neurons (Najafi-Marghmaleki et al., 2016). ANN is very productive for anticipating the information by learning through training. The ANN tool in Matlab Version 7.7.0.471 (R2008b) is employed for the study. In the current investigation, 60 experimental data are arbitrarily divided into three separate groups of training, testing and validation, respectively. $70 \%$ of the total number of experimental data are employed as training and validation sets; the remaining 30\% (not used for training or validation) for testing. Concentration and temperature are the input variables; and densities of BMImBr solutions as the output variable. The minimum and maximum of the variables in ANN are listed in Table 3.

The thermal conductivities of the $\mathrm{BMImBr}$ solutions within the training set are used as target values. All the target and input variables are normalized independently in the range 0 to 1 using Eq.5.

$$
\mathrm{x}^{\mathrm{n}}=\frac{\mathrm{x}_{\exp }-\min (\mathrm{x} \exp )}{\max \left(\mathrm{x}_{\exp }\right)-\min \left(\mathrm{x}_{\exp }\right)}
$$

where $x^{n}$ represents the normalized value of the variable, $x_{\text {exp }}$ is the actual experimental value of $x^{n}$, $\min \left(x_{\text {exp }}\right)$ is the minimum actual value of $x_{\text {exp }}, \max \left(x_{\text {exp }}\right)$ is the maximum actual value of $x_{e x}$

A feed forward back-propagation neural network with a single hidden layer is proposed since a network with only one hidden layer is able to correlate any complexities (Lashkarbolooki et al., 2013). The Levenberg-Marquardt training algorithm is used for training the network. Mean square error (MSE) is used as the performance function. The log-sigmoid transfer function, which is an appropriate choice for nonlinear functions (Haghbakhsh et al., 2013), is utilized as the activation function for input-hidden layers and the hidden to output layer employed the Purelin transfer function. These functions can be defined as follows:

Log-sigmoid transfer function

$z_{q}=f\left(y_{q}\right)=\frac{1}{1+e^{-y_{q}}}$ for $q=1$ to $r$

where $z_{q}$ is the output of the $q^{\text {th }}$ hidden neuron, $y_{q}$ is the input to the $q^{\text {th }}$ hidden neuron from the input layer given by Eq.7 and $r$ is the total number of hidden neurons in a first hidden layer.

$\mathrm{y}_{\mathrm{q}}=\sum_{\mathrm{p}=1}^{2} \mathrm{x}_{\mathrm{p}} \mathrm{nu}_{\mathrm{pq}}+\mathrm{a}_{\mathrm{q}}$

where $x_{p}^{n}$ represents the normalized input to the $p^{\text {th }}$ input neuron, $u_{p q}$ are the weights connecting $p^{\text {th }}$ input neuron to $q^{\text {th }}$ hidden neuron and $a_{q}$ is the bias to $q^{\text {th }}$ hidden neuron.

Purelin transfer function

$H=f(Z)=Z$

where $H$ is the output from the output neuron, $Z$ represents inputs to the output layer given by Eq. 9 .

$\mathrm{Z}=\sum_{\mathrm{q}=1}^{\mathrm{r}} \mathrm{z}_{\mathrm{q}} \mathrm{v}_{\mathrm{q} 1}+\mathrm{b}$

where $z_{q}$ represents the output of the $q^{\text {th }}$ hidden neuron in the hidden layer, $v_{q l}$ is the weight connecting the $q^{\text {th }}$ hidden neuron to the first output neuron and $b$ is the bias to the output neuron.

The optimum network is obtained by amending the number of hidden neurons in the hidden layer on a trial and error basis. The network is trained for 1000 epochs and all the other parameters are set to defaults as in the ANN tool. During training, the network parameters are periodically adjusted based on the comparison between the output and target values; until the number of epochs

Table 3. Ranges of the input and output variables in ANN.

\begin{tabular}{ccccc}
\hline Set & Variables & Unit & Minimum & Maximum \\
\hline Input & Concentration $(\mathrm{C})$ & $\% \mathrm{w} / \mathrm{w}$ & 0.1 & 0.6 \\
Output & Temperature $(\mathrm{T})$ & $\mathrm{K}$ & 302.5 & 337.9 \\
& Thermal Conductivity $(\mathrm{k})$ & $\mathrm{Wm}^{-1} \mathrm{~K}^{-1}$ & 1.50 & 2.91 \\
\hline
\end{tabular}


elapses or when the error reaches an acceptable level or when there is no improvement in the error generally. In this study, the training stops when the number of validation checks reaches six. Later, the network is tested with the testing set (data not used for training or validation) to check whether the trained network is able to reproduce the original data. The optimum ANN model is chosen by comparing the MSE (Eq.10), percentage average relative error (PARE) (Eq.11) and percentage average absolute error (PAAE) (Eq.12) of the testing data for different ANN models (Fatehi et al., 2014).

$$
\begin{aligned}
& \text { MSE }=\left(\frac{1}{N}\right) \sum_{n=1}^{N}\left(k_{n}{ }^{\text {exp }}-k_{n}^{\text {pre }}\right)^{2} \\
& \text { PARE }=\left(\frac{1}{N}\right) \sum_{n=1}^{N} \frac{\left(k_{n}^{\text {pre }}-k_{n}^{\text {exp }}\right)}{k_{n}^{\exp }} \times 100 \\
& \text { PAAE }=\left(\frac{1}{N}\right) \sum_{n=1}^{N}\left|\frac{\left(k_{n}^{\text {pre }}-k_{n}^{\text {exp }}\right)}{k_{n}^{\exp }}\right| \times 100
\end{aligned}
$$

In Eqs.10, 11, 12, $N$ represents the total number of testing data, $k_{n}{ }^{e x p}$ and $k_{n}^{p r e}$ are experimental and predicted thermal conductivity of the $n^{\text {th }}$ data in $\mathrm{Wm}^{-1} \mathrm{~K}^{-1}$.

\section{Nanoparticle size measurement}

$\mathrm{XRD}$ is the measuring technique used to confirm the crystallite size of the $\gamma-\mathrm{Al}_{2} \mathrm{O}_{3}$ nanoparticles. The XRD pattern obtained for the sample is shown in Figure 2. Significant peak broadening is obtained at a $2 \theta^{\circ}$ value of $66.926^{\circ}$. This peak is utilized for the crystallite size determination. The crystallite size is calculated using the Scherrer formula (Uvarov and Popov, 2007) given in Eq.13.

$$
\mathrm{d}=\frac{\mathrm{K} \lambda}{\beta \cos \theta}
$$

where $d$ is the crystallite size (nm), $K$ is the Scherrer constant, $\beta$ is the width of the peak or full width at half maximum (FWHM) in degrees, $\lambda$ is the $\mathrm{X}$-ray wavelength $(0.15406 \mathrm{~nm})$ and $\theta$ is the Bragg angle in degrees. The Scherrer constant usually varies from 0.8 1.39 and for spherical particles $K$ is nearly 1(Uvarov and Popov, 2007). With $\beta=0.7872^{\circ}, \theta=33.463^{\circ}$ and $K$ $=0.9$, the crystallite size is determined as $21 \mathrm{~nm}$, which lies in 20-30 nm size range as mentioned by the supplier.

\section{Nanofluid property determination}

The nanofluid with $\gamma-\mathrm{Al}_{2} \mathrm{O}_{3}$ nanoparticles dispersed in water as the base fluid is used for the study. The

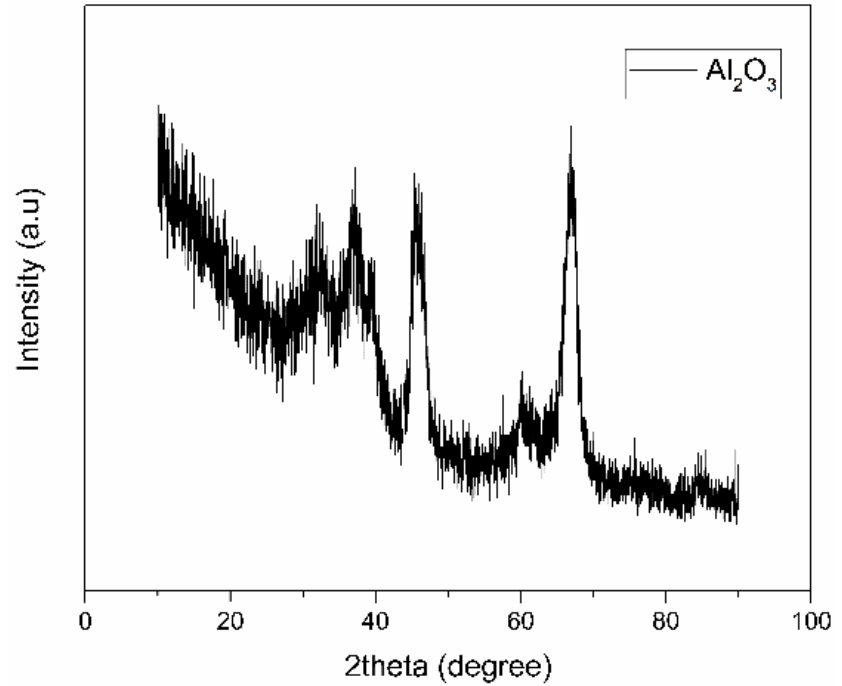

Figure 2. X-ray diffraction pattern obtained for $\gamma-\mathrm{Al}_{2} \mathrm{O}_{3}$ nanoparticle.

thermophysical properties of $\gamma-\mathrm{Al}_{2} \mathrm{O}_{3}$ nanoparticles are: density $\rho_{n p}=3700 \mathrm{kgm}^{-3}$ and thermal conductivity $k_{n p}=46 \mathrm{Wm}^{-1} \mathrm{~K}^{-1}$ (Farajollahi et al., 2010). The thermal conductivity of the $\gamma-\mathrm{Al}_{2} \mathrm{O}_{3} /$ water nanofluid is determined for different concentrations ranging from $0.1-0.6 \% \mathrm{w} / \mathrm{w}$ using the Maxwell equation (Perarasu et al., 2013) given by Eq.14.

$\frac{\mathrm{k}_{\mathrm{nf}}}{\mathrm{k}_{\mathrm{bf}}}=\frac{\mathrm{k}_{\mathrm{np}}+2 \mathrm{k}_{\mathrm{bf}}+2 \varphi\left(\mathrm{k}_{\mathrm{np}}-\mathrm{k}_{\mathrm{bf}}\right)}{\mathrm{k}_{\mathrm{np}}+2 \mathrm{k}_{\mathrm{bf}}-\varphi\left(\mathrm{k}_{\mathrm{np}}-\mathrm{k}_{\mathrm{bf}}\right)}$

where $k_{n f}, k_{b f}$ and $k_{n p}$ are the thermal conductivity of the nanofluid, basefluid and nanoparticle in $\mathrm{Wm}^{-}$ ${ }^{1} \mathrm{k}^{-1}$ and $\varphi$ represents volume fraction. If the thermal conductivity of the nanoparticle is much higher than that of the base liquid then Eq.15 can be used for determining the nanofluid thermal conductivity (Perarasu et al., 2013).

$\mathrm{k}_{\mathrm{nf}}=\mathrm{k}_{\mathrm{bf}}(1+3 \varphi)$

where $k_{n f}$ and $k_{b f}$ are the thermal conductivity of nanofluid and basefluid, and $\varphi$ represents volume fraction. The nanofluid in weight concentration is converted into volume concentration using Eq.16.

$$
\varnothing=\frac{\mathrm{m}_{\mathrm{np}} \rho_{\mathrm{bf}}}{\frac{\mathrm{m}_{\mathrm{p}}}{100} \rho_{\mathrm{bf}}+\left(1-\frac{\mathrm{m}_{\mathrm{p}}}{100}\right) \rho_{\mathrm{np}}}
$$

where $\phi$ is the volume concentration $(\phi=100 \varphi)$ in $\% \mathrm{v} / \mathrm{v}, m_{n p}$ is the weight concentration in $\% \mathrm{w} / \mathrm{w}, \rho_{b f}$ and $\rho_{n p}$ represent the density of basefluid and nanoparticle in $\mathrm{kg} \mathrm{m}^{-3}$ (Azmi et al., 2013). 


\section{RESULTS AND DISCUSSION}

The experimental thermal conductivities estimated for varying concentrations of $\mathrm{BMImBr}$ solutions $(0.1$ $0.6 \% \mathrm{w} / \mathrm{w})$ at different temperatures (302.52 - 337.92 $\mathrm{K})$ under ambient pressure are analyzed. In addition, the thermal conductivities of the BMImBr solution are compared with those of $\gamma-\mathrm{Al}_{2} \mathrm{O}_{3} /$ water nanofluid and the results are presented as follows.

\section{Effects of Temperature and Concentration on thermal conductivity of $\mathrm{BMImBr}$ solution}

The effect of temperature and concentration on the thermal conductivity of BMImBr solutions are plotted in Figure 3. The thermal conductivities vary from 1.5$2.9 \mathrm{Wm}^{-1} \mathrm{~K}^{-1}$ for $0.1-0.6 \% \mathrm{w} / \mathrm{w}$ solutions of $\mathrm{BMImBr}$ in the temperatures $302.5-337.9 \mathrm{~K}$ under ambient pressure. From Figure 3, it is evident that thermal conductivity of the aqueous BMImBr solutions decreases with the increase in concentration and temperature. As the temperature of the solution increases, the probability of collision between molecules increases. Hence, the mean free path of the molecules decreases, thereby reducing the thermal conductivity. The thermal conductivity of organic liquids like benzene, toluene, ethylene glycol etc., also decreases with an increase in temperature (Ge et al., 2007). Similar behavior is noted for other pure ionic liquids too (Castro et al., 2010; Valkenburg et al., 2005).

The thermal conductivity decreases with the increase in the concentration of BMImBr, irrespective of temperature. As the concentration increases, the solution viscosity increases whereby reducing the ion mobility. Additionally, the poor intermolecular interaction between ionic liquid and water reduces thermal conductivity. The incremental addition of pure ionic liquid to the solution (ionic liquid + water) reduces the thermal conductivity of the resultant solution (Valkenburg et al., 2005). 1-Ethyl-3-methylimidazol-

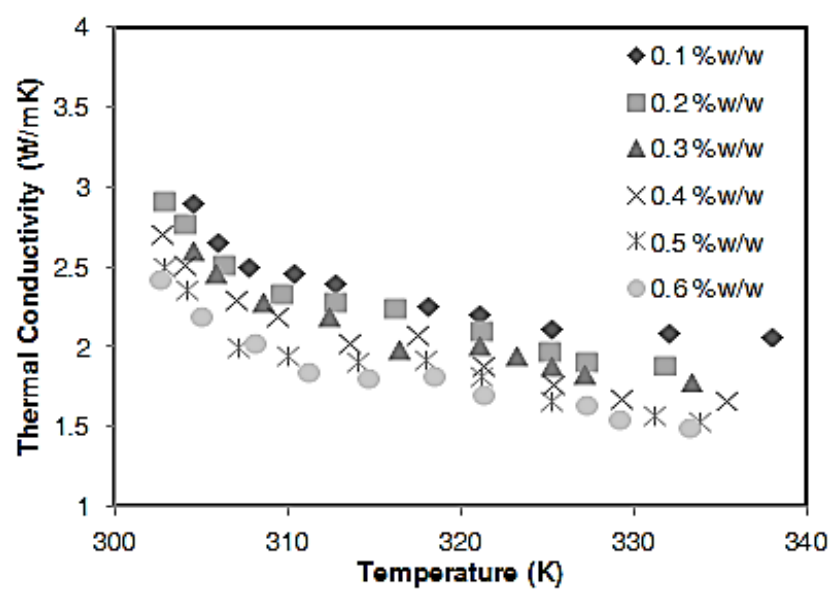

Figure 3. Effect of temperature and concentration on thermal conductivity of BMImBr solutions 3-ium ethylsulphate ([EMIM][EtSO $]$ ) + water mixtures also showed a similar trend of decrease in the thermal conductivity with increase in the mass fraction of [EMIM] $\left[\mathrm{EtSO}_{4}\right]$ (Chen et al., 2013). The thermal conductivity of the BMImBr + water binary solutions is much greater than the thermal conductivity of water, which means that BMImBr may be used as an additive with water for enhanced performance as a heat transfer fluid.

RSM model analysis of the thermal conductivity of aqueous BMImBr solution

Experimental design

The experimental results obtained are used to determine the model equation for the thermal conductivity of BMImBr solutions using the CCFCD under the RSM, with temperature and concentration as the independent variables.

The final quadratic model regression equation in terms of actual factors as obtained in RSM is given below:

$$
\begin{aligned}
\mathrm{k}_{\mathrm{io}}{ }^{\text {pre }} & =64.280-0.3610 \mathrm{~T}+0.5015 \mathrm{C}- \\
& -0.0061 \mathrm{TC}+0.6170 \mathrm{C}^{2}+0.000525 \mathrm{~T}^{2}
\end{aligned}
$$

where $k_{i o}{ }^{p r e}$ is the predicted thermal conductivity of the BMImBr solution $\left(\mathrm{Wm}^{-1} \mathrm{~K}^{-1}\right), T$ is temperature $(\mathrm{K})$ and $C$ is the concentration of BMImBr solution $(\% \mathrm{w} / \mathrm{w})$.

The ANOVA test (Table 4) is used to determine the significant effects of the operating variables such as temperature and concentration. An F value $=481.90$ for temperature indicated that it is the most significant variable affecting thermal conductivity of $\mathrm{BMImBr}$ followed by concentration $(\mathrm{F}=153.37)$ and then $T^{2}$ $(F=15.85)$. The source terms with ' $p$ value $=$ Prob $>F$ ' less than 0.05 implies that the source terms (model, concentration, temperature and $T^{2}$ ) are significant. The terms with 'p-value' more than 0.05 are also considered in the developed model equation (Eq.17) to minimize the error of the prediction model. The validity of the developed model is assured by comparison with the experimental values and Figure 4 shows that the values are close to the diagonal line, indicating that the errors between the experimental values and the predicted values are minimal. The quadratic regression model of thermal conductivity of BMImBr solution designates the coefficient of determination $R^{2}$ and adjusted $R^{2}$ as 0.990 and 0.982 , respectively, hence demonstrating the quality of the best fit of the determined quadratic model.

Combined effects of concentration and temperature on the thermal conductivity of aqueous ionic liquid solutions

The response surface curve for the thermal conductivity of BMImBr solutions is plotted using 
Table 4. ANOVA table for the RSM quadratic model of thermal conductivity.

\begin{tabular}{ccccccc}
\hline Source & $\begin{array}{c}\text { Sum of } \\
\text { Squares }\end{array}$ & $\begin{array}{c}\text { Degrees of } \\
\text { freedom (df) }\end{array}$ & $\begin{array}{c}\text { Mean } \\
\text { Square }\end{array}$ & $\begin{array}{c}\text { F } \\
\text { Value }\end{array}$ & $\begin{array}{c}\text { p-value } \\
\text { Prob }>\text { F }\end{array}$ & Remarks \\
\hline Model & 1.61 & 5 & 0.32 & 132.25 & $<0.0001$ & Significant \\
A - Temperature & 1.17 & 1 & 1.17 & 481.90 & $<0.0001$ & Most significant \\
B - Concentration & 0.37 & 1 & 0.37 & 153.37 & $<0.0001$ & Significant \\
AB & 0.002 & 1 & 0.002 & 0.85 & 0.3866 & Significant \\
A $^{2}$ & 0.039 & 1 & 0.039 & 15.85 & 0.0053 & Significant \\
B $^{2}$ & 0.004 & 1 & 0.004 & 1.69 & 0.2346 & Significant \\
Residual & 0.017 & 7 & 0.002 & & & Not significant \\
Lack of Fit & 0.014 & 3 & 0.004 & 6.33 & 0.0534 & \\
Pure Error & 0.003 & 4 & 0.007 & & & \\
Core Total & 1.62 & 12 & & & & \\
\hline
\end{tabular}

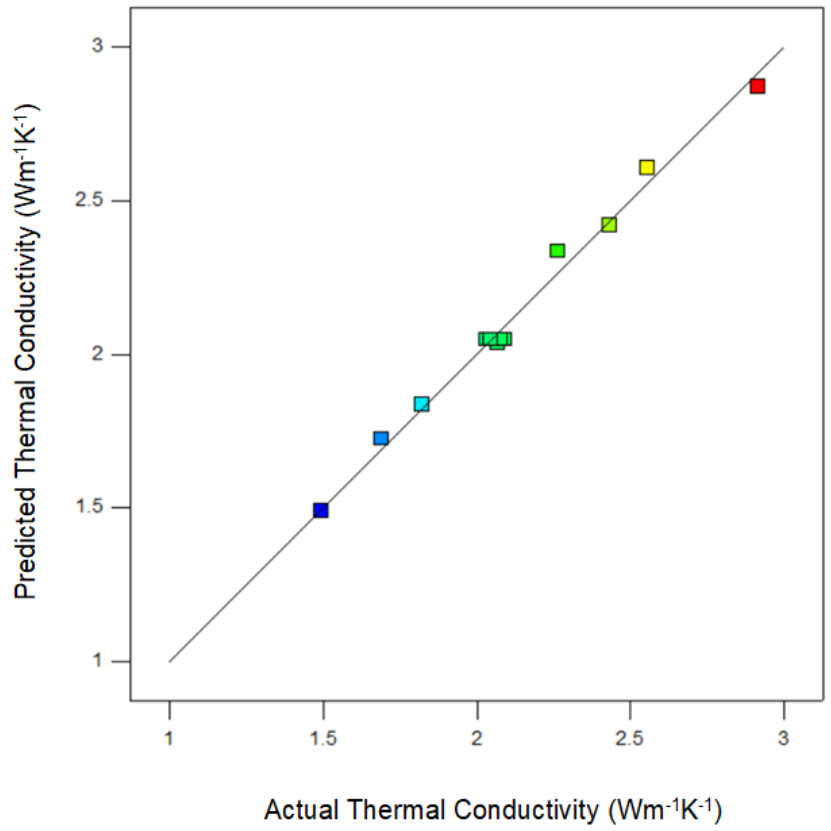

Figure 4. Comparison between predicted and experimental thermal conductivities of $\mathrm{BMImBr}$ solutions.

the generated Eq.17 to investigate the combined effects of temperature and concentration (Figure 5). The response surface shows good agreement with the experimental results. From Figure 5, it is evident that,

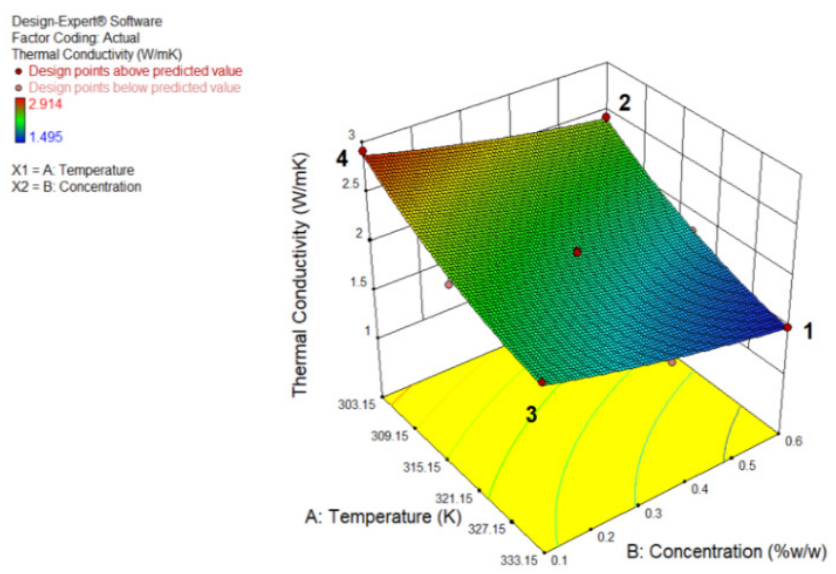

Figure 5. Response surface plot showing the effects on thermal conductivity for BMImBr solutions as the concentration and temperature of the BMImBr solution increases, the thermal conductivity decreases. For instance, from $2 \rightarrow 4$ thermal conductivity increases from $2.43 \mathrm{Wm}^{-1} \mathrm{~K}^{-1}$ to $2.91 \mathrm{Wm}^{-1} \mathrm{~K}^{-1}$ at a particular temperature $(303.15 \mathrm{~K})$ with a decrease in concentration $(0.6 \rightarrow 0.1 \% \mathrm{w} / \mathrm{w})$. As the temperature increases from $303.15-333.15 \mathrm{~K}$ (say, $2 \rightarrow 1$ ), thermal conductivity at a particular concentration $(0.6 \% \mathrm{w} / \mathrm{w})$ decreases. $1 \rightarrow 3$ indicates the lowest values of thermal conductivity while $2 \rightarrow 4$ signals the highest values. Thus, the impacts of both temperature and concentration are broadly studied and can be quantified from the RSM plot.

\section{ANN analysis of the thermal conductivity of aqueous $B M I m B r$ solution}

The performance of the investigated ANN models is shown in Figure 6. It is clear that the predicted responses of the network are affected by changing the number of neurons in the hidden layer. In this study, only a single hidden layer is considered for modeling, as a two-layered (input-output and one hidden layer) network itself is efficient for predicting data with greater accuracy (Lashkarbolooki et al., 2013). The ANN network 2-10-1 (two input neurons, one hidden layer with ten hidden neurons and one neuron in the output layer) with the least $M S E=0.005, P A R E=$ -1.398 and $P A A E=2.685$, compared to other networks, is chosen as the optimum network (Figure 7).

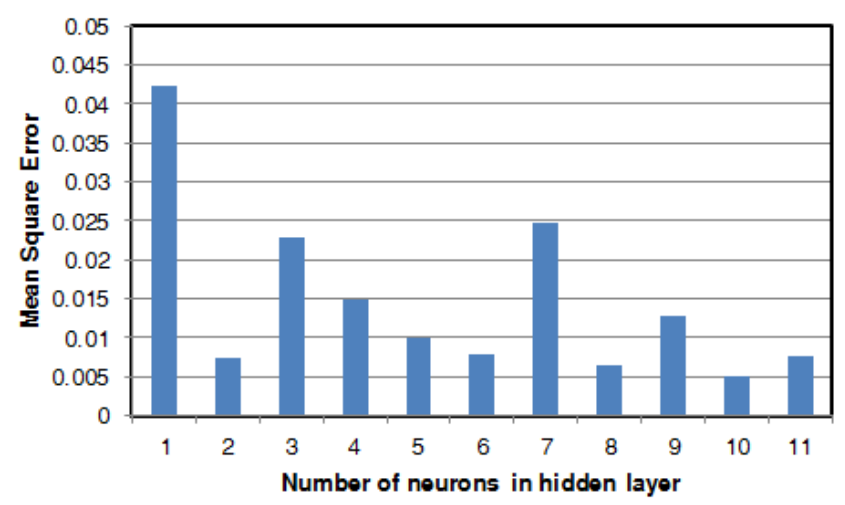

Figure 6. Comparison of MSE of test data for three layered architecture of ANN. 


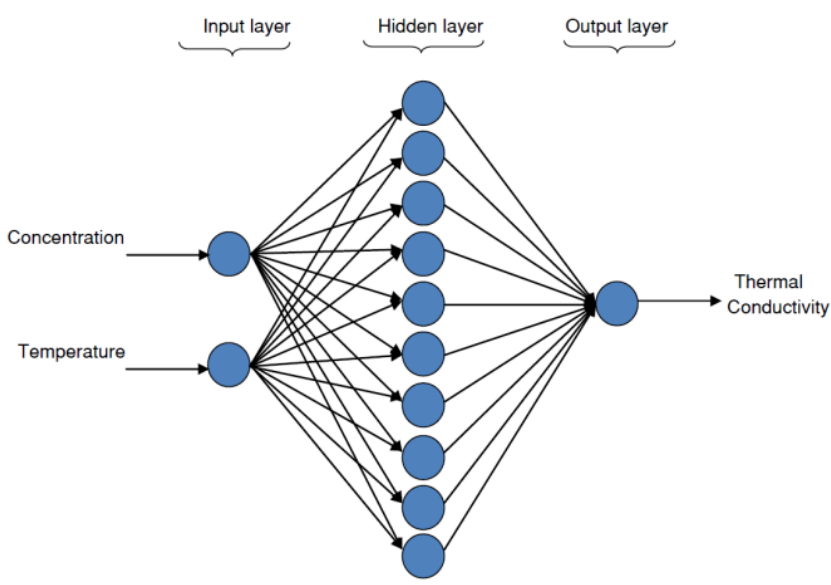

Figure 7. Optimized Neural Network model: 2-10-1.

The regression and performance plots are generated after training the ANN networks to check the regression coefficient and MSE of training, validation and testing sets. Training is stopped when fairly good regression coefficients are achieved for all training, testing and validation sets. From the regression plot (Figure 8), it is clear that the cluster line and the fit data line almost coincide with each other with $R^{2}$ values of $0.9995,0.9845$ and 0.9589 for training, testing and validation sets, respectively. This indicates that the model predictions and the experimental data are in excellent agreement. The parameters associated with each neuron (weight and bias) in the input-hidden and hidden-output layers of the ANN network are updated automatically during iteration until the number of validation checks became equal to six. Table 5 indicates the weights and biases of the optimized network (2-10-1).

\section{Comparison of RSM and ANN thermal conductivity models of aqueous BMImBr solution}

The thermal conductivity predicted by RSM and ANN are compared with the experimental thermal conductivities of BMImBr solutions (data included for its modeling is not considered) based on the statistical quality parameters $M S E$, Root Mean Square Error (RMSE) (as given in Eq.18) and PAAE (Table 6).
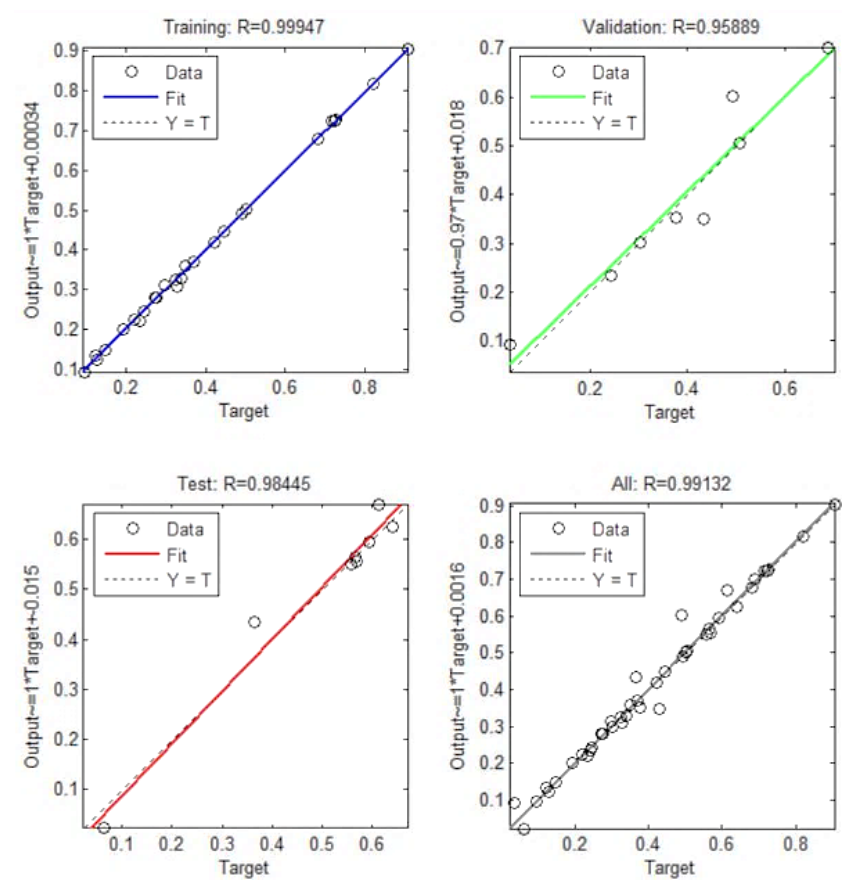

Figure 8. Regression plots of optimized model 2-10-1.

RMSE $=\left[\left(\frac{1}{N}\right) \sum_{n=1}^{N}\left(k_{n}{ }^{\text {exp }}-k_{n}{ }^{\text {pre }}\right)^{2}\right]^{1 / 2}$

where $N$ represents the total number of test data, $k_{n}^{\exp }$ and $k_{n}^{p r e}$ are the actual value of the experimental and predicted thermal conductivity of the $\mathrm{n}^{\text {th }}$ data.

Based on the lower values of $M S E=0.005, R M S E$ $=0.071$ and $P A A E=2.684$, it is clear that the ANN model is more robust and accurate than the RSM model.

\section{Comparison of the thermal conductivity of aqueous $\mathrm{BMImBr} /$ water and $\gamma-\mathrm{Al}_{2} \mathrm{O}_{3}$ /water nanofluid}

Research on nanofluids and ionic liquids has increased tremendously. This interest is mainly rooted in the unique properties of ionic liquids and nanofluids. The thermal conductivity of $\gamma-\mathrm{Al}_{2} \mathrm{O}_{3} /$ water nanofluid (nanoparticle: $\gamma-\mathrm{Al}_{2} \mathrm{O}_{3}$, base fluid: water) in the concentrations ranging from $0.1-0.6 \% \mathrm{w} / \mathrm{w}$

Table 5. Weight and bias values of the neurons in the optimized 2-10-1 network.

\begin{tabular}{|c|c|c|c|c|c|}
\hline \multirow{2}{*}{$\begin{array}{c}\text { Neurons } \\
\text { in hidden } \\
\text { layer, } q \\
\end{array}$} & \multicolumn{2}{|c|}{$\begin{array}{l}\text { Weights of the input neurons } \\
\text { to the hidden layer, } u_{p q}\end{array}$} & \multirow{2}{*}{$\begin{array}{c}\text { Bias to } \\
\text { the hidden layer, } a_{q}\end{array}$} & \multirow{2}{*}{$\begin{array}{c}\text { Weight of } \\
\text { the hidden neurons to } \\
\text { the output layer, } v_{q I}\end{array}$} & \multirow{2}{*}{$\begin{array}{l}\text { Bias to } \\
\text { the output } \\
\text { layer, } b\end{array}$} \\
\hline & Concentration, $\boldsymbol{u}_{1 q}$ & Temperature, $\boldsymbol{u}_{2 q}$ & & & \\
\hline 1 & 6.1066 & -5.8429 & -9.317 & 0.97535 & \multirow{10}{*}{-0.090542} \\
\hline 2 & 5.747 & -5.736 & -8.7617 & -0.44825 & \\
\hline 3 & 4.9907 & 5.4696 & -5.5286 & -0.35774 & \\
\hline 4 & -7.6128 & -4.6048 & 3.0947 & 0.082262 & \\
\hline 5 & -7.5678 & -4.2775 & 0.99717 & 0.26332 & \\
\hline 6 & -8.0673 & 4.2054 & -0.8497 & 0.050979 & \\
\hline 7 & 3.8441 & -7.7715 & 2.409 & 0.18019 & \\
\hline 8 & 5.989 & 8.0523 & 3.3064 & -0.32078 & \\
\hline 9 & 8.3117 & -0.5513 & 7.8526 & -0.30461 & \\
\hline 10 & -2.1306 & -8.9977 & -8.7603 & 1.0338 & \\
\hline
\end{tabular}


Table 6. Comparison of RSM and ANN models.

\begin{tabular}{|c|c|c|c|c|c|}
\hline \multirow{2}{*}{$\begin{array}{l}\text { S. } \\
\text { No. }\end{array}$} & \multirow{2}{*}{$\begin{array}{c}\text { Concentration } \\
(\% \mathrm{w} / \mathrm{w})\end{array}$} & \multirow{2}{*}{$\begin{array}{c}\text { Temperature } \\
\text { (K) }\end{array}$} & \multicolumn{3}{|c|}{ Thermal Conductivity $\left(\mathrm{Wm}^{-1} \mathrm{~K}^{-1}\right)$} \\
\hline & & & Experimental & RSM & $\begin{array}{c}\text { ANN } \\
(2-10-1)\end{array}$ \\
\hline 1 & 0.1 & 304.5 & 2.91 & 2.90 & 2.93 \\
\hline 2 & 0.1 & 318.1 & 2.26 & 2.43 & 2.29 \\
\hline 3 & 0.1 & 337.9 & 2.08 & 2.09 & 2.08 \\
\hline 4 & 0.2 & 302.8 & 2.93 & 2.86 & 2.84 \\
\hline 5 & 0.2 & 316.2 & 2.25 & 2.36 & 2.21 \\
\hline 6 & 0.2 & 331.8 & 1.89 & 2.02 & 1.94 \\
\hline 7 & 0.3 & 304.5 & 2.62 & 2.68 & 2.61 \\
\hline 8 & 0.3 & 321.0 & 2.02 & 2.11 & 1.99 \\
\hline 9 & 0.3 & 333.3 & 1.79 & 1.88 & 1.71 \\
\hline 10 & 0.4 & 302.6 & 2.71 & 2.68 & 2.69 \\
\hline 11 & 0.4 & 317.4 & 2.09 & 2.11 & 1.94 \\
\hline 12 & 0.4 & 335.3 & 1.67 & 1.74 & 1.55 \\
\hline 13 & 0.5 & 302.8 & 2.51 & 2.59 & 2.65 \\
\hline 14 & 0.5 & 317.9 & 1.93 & 2.00 & 1.83 \\
\hline 15 & 0.5 & 333.8 & 1.54 & 1.66 & 1.52 \\
\hline 16 & 0.6 & 302.5 & 2.43 & 2.533 & 2.45 \\
\hline 17 & 0.6 & 318.4 & 1.82 & 1.92 & 1.75 \\
\hline 18 & 0.6 & 333.1 & 1.50 & 1.59 & 1.51 \\
\hline \multicolumn{4}{|c|}{ MSE } & 0.008 & 0.005 \\
\hline \multicolumn{4}{|c|}{ RMSE } & 0.089 & 0.071 \\
\hline \multicolumn{3}{|r|}{ PAAE } & & 3.979 & 2.684 \\
\hline
\end{tabular}

and temperature range $302.52-337.92 \mathrm{~K}$ calculated using Eq.16 is compared with BMImBr ionic liquid solution at the same concentration and temperature. The effect of temperature and concentration on the thermal conductivity of $\gamma-\mathrm{Al}_{2} \mathrm{O}_{3} /$ water nanofluid is depicted in Figure 9. The aforementioned nanofluid thermal conductivity increases with an increase in the temperature and concentration of the nanoparticle. The same trend is also reported for other nanofluids (Li and Xuan, 2000; Perarasu et al., 2013). As nanofluids are suspensions of the nanoparticles in the base fluid, the enhancement in the thermal conductivity of the base fluid is due to the motion of the nanoparticles dispersed in the basefluid ( $\mathrm{Li}$ and Xuan, 2000; Perarasu et al., 2013). However, the thermal conductivity of $\mathrm{BMImBr} /$ water ionic liquid solution decreases with an increase in temperature and concentration as shown in Figure 3. In the case

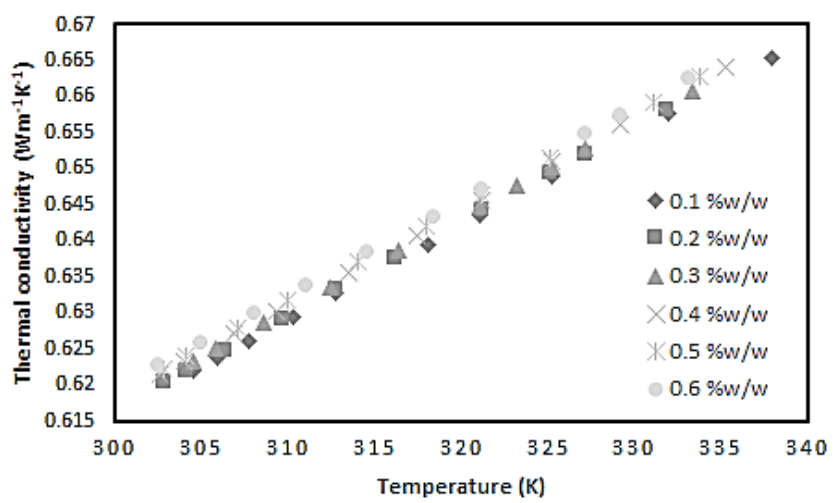

Figure 9. Effect of temperature and concentration on $\gamma-\mathrm{Al}_{2} \mathrm{O}_{3} /$ water nanofluid. of ionic liquid solutions, the reverse behavior may be due to the interactions between the ions of ionic liquid and water.

The effect of concentration is greater for $\mathrm{BMImBr} /$ water compared to $\gamma$ - $\mathrm{Al}_{2} \mathrm{O}_{3}$ /water nanofluid. From Figure 10, it can be clearly inferred that the thermal conductivity of the $\mathrm{BMImBr} /$ water solution $\left(k_{i 0}\right)$ is much higher than the thermal conductivity of the $\gamma-\mathrm{Al}_{2} \mathrm{O}_{3}$ /water nanofluid $\left(k_{n f}\right)$ in the concentration range $(0.1-0.6 \% \mathrm{w} / \mathrm{w})$ studied. The enhancement ratio $\left(k_{n f} / k_{b f}\right.$ or $\left.k_{i o} / k_{b f}\right)$ is evaluated for both aqueous BMImBr solution and $\gamma-\mathrm{Al}_{2} \mathrm{O}_{3} /$ water nanofluid at $302.52 \mathrm{~K}$ and plotted in Figure 11. The enhancement ratio values of the aqueous $\mathrm{BMImBr}$ solution are much higher than of $\gamma-\mathrm{Al}_{2} \mathrm{O}_{3} /$ water nanofluid. For instance, for 0.1 $\% \mathrm{w} / \mathrm{w}$ concentration, the values are $k_{n f} k_{b f}=1.00$ and $k_{i o} / k_{b f}=4.22$ for $\gamma-\mathrm{Al}_{2} \mathrm{O}_{3} /$ water nanofluid and aqueous BMImBr solution, respectively.

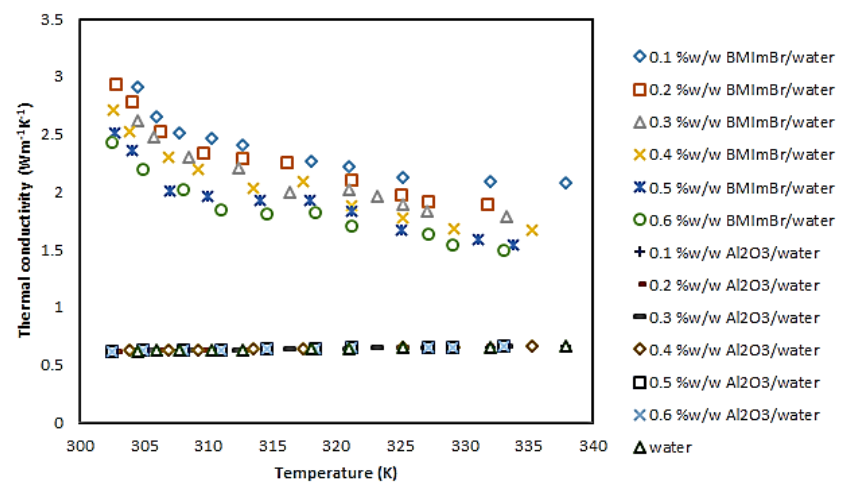

Figure 10. Comparison of thermal conductivity of $\gamma-\mathrm{Al}_{2} \mathrm{O}_{3}$ /water nanofluid and aqueous BMImBr solution. 


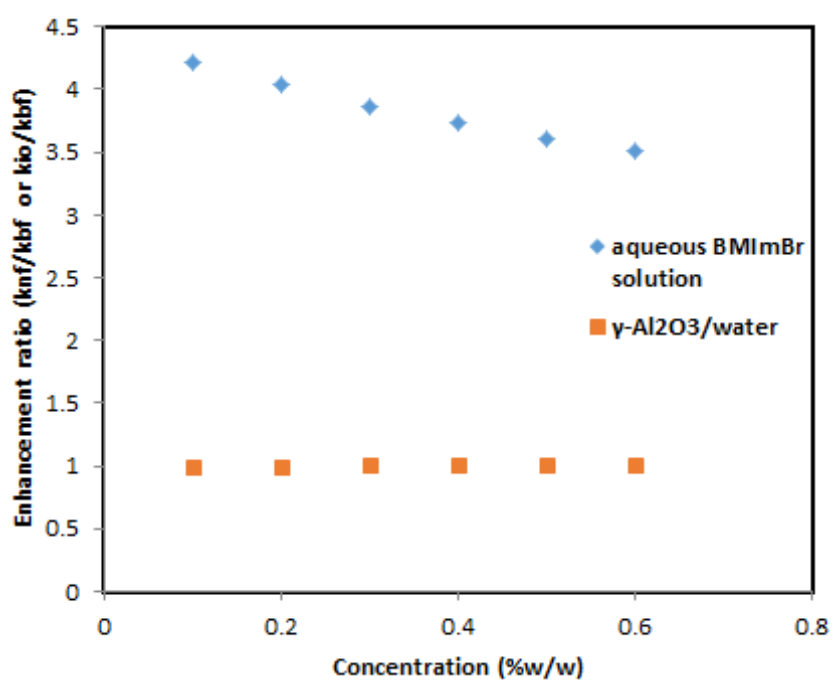

Figure 11. Enhancement ratio comparison of $\gamma-\mathrm{Al}_{2} \mathrm{O}_{3} /$ water nanofluid and aqueous $\mathrm{BMImBr}$ solution at $302.52 \mathrm{~K}$.

\section{CONCLUSION}

The thermal conductivities of aqueous BMImBr solutions are determined at different temperatures ranging from 302.52-337.92 $\mathrm{K}$ and $0.1-0.6 \% \mathrm{w} / \mathrm{w}$ concentrations under ambient pressure. The thermal conductivity is measured using the thermal conductivity apparatus that works based on the guarded hot plate method. The experimental thermal conductivity values of the ionic liquid vary in the range of 1.495-2.914 $\mathrm{Wm}^{-1} \mathrm{~K}^{-1}$ for the range of concentration and temperature studied. A second order quadratic equation with a coefficient of determination $\mathrm{R}^{2}$ of 0.990 is formulated to compute the thermal conductivity of $\mathrm{BMImBr}$ solution using RSM with $M S E=2.212, P A R E=$ 4.474 and $P A A E=4.474$. From ANOVA analysis, it is found that temperature is a more significant operating variable influencing the thermal conductivity than the concentration.

A two-layered feed forward back-propagation neural network is also developed for predicting the thermal conductivity of aqueous BMImBr solutions. An ANN model with two input neurons, ten hidden neurons and one output neuron is the optimum architecture obtained with $M S E=0.005, P A R E=-1.398$ and $P A A E=2.684$. The statistical methods specified that both the models are explicit in the prediction of experimental thermal conductivities of $\mathrm{BMImBr}$ solutions. However, the ANN model demonstrated better performance compared to the RSM model owing to lower values of $M S E=0.005, R M S E=0.0714$ and $P A A E=2.684$. The proposed models are useful in predicting the thermal conductivities of BMImBr solutions at the required temperature and concentration without conducting any further experiments. However, the pertinence of the proposed models can further be enhanced by covering

an extensive range of concentration and temperature values.

The comparison studies of the thermal conductivity of $\mathrm{BMImBr} /$ water and $\gamma-\mathrm{Al}_{2} \mathrm{O}_{3} /$ water nanofluid in the concentration range from $0.1-0.6 \% \mathrm{w} / \mathrm{w}$ are conducted. The thermal conductivity of $\gamma-\mathrm{Al}_{2} \mathrm{O}_{3}$ /water varied in the range of $0.622-0.665 \mathrm{Wm}^{-1} \mathrm{~K}^{-1}$ in the temperature ranges of $302.52-337.92 \mathrm{~K}$ and $0.1-0.6 \% \mathrm{w} / \mathrm{w}$ concentrations under ambient pressure. The results of the study indicate that the thermal conductivity values of both the fluids, namely BMImBr/water and $\gamma-\mathrm{Al}_{2} \mathrm{O}_{3} /$ water, are higher than that of water. But the thermal conductivity values of the BMImBr/water solution is much higher compared to $\gamma-\mathrm{Al}_{2} \mathrm{O}_{3} /$ water nanofluid. For instance, at $0.1 \% \mathrm{w} / \mathrm{w}$ concentration and $302.52 \mathrm{~K}$, thermal conductivity enhancement ratios equal to 1.00 and 4.22 are obtained for $\gamma-\mathrm{Al}_{2} \mathrm{O}_{3}$ /water nanofluid and $\mathrm{BMImBr} /$ water, respectively. Hence, this remarkable thermal conductivity enhancement suggests that these two liquids may be used effectively in heat transfer applications to improve the thermal conductivity of conventional water-based heat transfer fluids.

\section{NOMENCLATURE}

\section{$D$}

$I$

$\Delta X$

D $x_{\text {exp }}$ F Y

Z $\max \left(x_{\text {exp }}\right)$ $\min \left(x_{\text {exp }}^{\text {exp }}\right)$ $x^{n}$ H H $Z$
$Y$ K B T k
Amount of heat transferred through the liquid at steady state, $\mathrm{W}$ Area of heat transfer, $\mathrm{m}^{2}$ Average face temperature of the cold plate, $\mathrm{K}$

Average face temperature of the hot plate, $\mathrm{K}$

Bias to the hidden layer

Bias to the output neuron

Concentration of BMImBr solution, $\% \mathrm{w} / \mathrm{w}$

Crystalline size, nm

Current, A

Depth of the sample, $m$

Diameter of the plate, $\mathrm{m}$

Experimental value of $x^{n}$

First Independent Variable

Fisher value

Input to hidden neuron

Input to output layer

Maximum value of $x_{\text {exp }}$

Minimum value of $x$

Normalized value of the variable

Output from output neuron

Output of hidden neuron

Response variable

Scherrer constant

Second Independent Variable

Temperature of BMImBr solution, $\% \mathrm{w} / \mathrm{w}$

Thermal conductivity, $\mathrm{Wm}^{-1} \mathrm{~K}^{-1}$ 
$R \quad$ Total number of hidden neurons in the

first hidden layer

$N \quad$ Total number of test data

E Voltage, V

M Weight concentration of nanoparticle, $\% \mathrm{w} / \mathrm{w}$

$V \quad$ Weights connecting hidden to output neuron

$U \quad$ Weights connecting input to hidden neuron

\section{Greek symbols}

$\Theta \quad$ Bragg angle, degrees

$\beta \quad$ Constant

$P \quad$ Density, $\mathrm{kgm}^{-3}$

$\beta_{5} \quad$ Interaction coefficient

$\beta_{2} \quad$ Linear coefficient of B

$\beta_{1} \quad$ Linear coefficient of $\mathrm{A}$

$\beta_{3} \quad$ Quadratic coefficient of A

$\beta_{4} \quad$ Quadratic coefficient of B

$\Phi \quad$ Volume concentration, $\% \mathrm{v} / \mathrm{v}$

$\Phi \quad$ Volume fraction

$B \quad$ Width of peak, degrees

A X-Ray wavelength, nm

\section{Subscripts}

$\begin{array}{ll}\text { Bf } & \text { Base fluid } \\ \mathrm{C} & \text { Cold plate } \\ \mathrm{Q} & \text { Hidden neuron } \\ \mathrm{H} & \text { Hot plate } \\ \mathrm{P} & \text { Input neuron } \\ \mathrm{Io} & \text { Ionic liquid } \\ \mathrm{Np} & \text { Nanoparticle } \\ \mathrm{N} & \mathrm{n}^{\text {th }} \text { testing data }\end{array}$

\section{Superscripts}

exp Experimental value

N Normalized value

Pre Predicted value

\section{Abbreviations}

$\mathrm{BMImBr}$

1-Butyl-3-methylimidazolium bromide

ANN Artificial neural network

CCD Central composite design

CCFCD Central composite face centered design

$\mathrm{R}^{2} \quad$ Coefficient of determination

$\gamma-\mathrm{Al}_{2} \mathrm{O}_{3} \quad$ Gamma Aluminium Oxide

$\mathrm{MSE} \quad$ Mean square error

$P A A E \quad$ Percentage average absolute error

$P A R E \quad$ Percentage average relative error

RTD-PT Resistance temperature detectors-

Platinum thermometers

RSM Response Surface Methodology

RMSE Root Mean Square Error

XRD X-ray diffraction

\section{REFERENCES}

Abdullah, S.B., Man, Z., Bustam, M. An Optimization Study via Response Surface Methodology in Extracting of Benzothiophene and Xylene from n- $\mathrm{C}_{12}$ using 1-Hexyl-3-Methylimidazolium Tetrafluoroborate Ionic liquid. J. Appl. Sci., 14, 1008-1015 (2014). https://doi.org/10.3923/ jas.2014.1008.1015

Albert, J., Muller, K. Thermal conductivity of Ionic Liquids: An estimation approach, Chem. Eng. Sci. 119, 109-113 (2014). https://doi.org/10.1016/j. ces.2014.08.023

Amarasekara, A.S., Owereh, O.S. Thermal properties of sulfonic acid group functionalized Bronsted acidic ionic liquids. J. Therm. Anal. Calorim., 103, 1027-1030 (2011). https://doi.org/10.1007/s10973$010-1101-5$

Aybar, H., Sharifpur, M., Azizian, M.R., Mehrabi, M., Meyer, J.P. A review of thermal conductivity models for nanofluids. Heat Transf. Eng., 36, 10851110 (2015). https://doi.org/10.1080/01457632.20 15.987586

Azmi, W.H., Sharma, K. V., Sarma, P.K., Mamat, R., Anuar, S., Rao, V.D. Experimental determination of turbulent forced convection heat transfer and friction factor with $\mathrm{SiO}_{2}$ nanofluid. Exp. Therm. Fluid Sci., 51, 103-111 (2013). https://doi. org/10.1016/j.expthermflusci.2013.07.006

Biniaz, P., Farsi, M., Rahimpour, M.R. Demulsification of water in oil emulsion using ionic liquids: Statistical modeling and optimization. Fuel 184, 325-333 (2016). https://doi.org/10.1016/j. fuel.2016.06.093

Carrete, J., Mendez-Morales, T., Garcia, M., Vila, J., Cabeza, O., Gallego, L.J., Varela, L.M. Thermal Conductivity of Ionic Liquids: A Pseudolattice Approach. J. Phys. Chem., 116, 1265-1273 (2012). https://doi.org/10.1021/jp208972t

Castro, C.A.N., Lourenco, A.P., Ribeiro, A.P.C., Langa, E., Vieira, S.I.C., Goodrich, P., Hardacre, C. Thermal properties of ionic liquids and ionanofluids of imidazolium and pyrrolidinium liquids. J. Chem. Eng. Data, 55, 653-661 (2010). https://doi. org $/ 10.1021 /$ je $900648 p$

Chen, Q.-L., Wu, K.-J., He, C.-H., Thermal Conductivity of Ionic Liquids at Atmospheric Pressure: Database, Analysis, and Prediction Using a Topological Index Method. Ind. Eng. Chem. Res., 53, 7224-7232 (2014). https://doi.org/10.1021/ ie $403500 \mathrm{w}$

Chen, Q.-L., Wu, K.-J., He, C.-H., Thermal

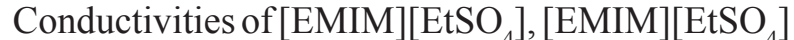
$+\mathrm{C}_{2} \mathrm{H}_{5} \mathrm{OH}+\mathrm{H}_{2} \mathrm{O}$ at $\mathrm{T}=(283.15 \mathrm{TO} 343.15) \mathrm{K}$. J. Chem. Eng. Data, 58, 2058-2064 (2013). https:// doi.org/10.1021/je400268t 
Chernikova, E.A., Glukhov, L.M., Krasovskiy, V.G., Kustov, L.M., Vorobyeva, M.G., Koroteev, A.A. Ionic liquids as heat transfer fluids: Comparison with known systems, possible applications, advantages and disadvantages. Russ. Chem. Rev., 84, 875-890 (2015). https://doi.org/10.1070/ RCR 4510

Choi, S.U.S., Eastman, J.A. Enhancing thermal conductivity of fluids with nanoparticles, in: ASME International Mechanical Engineering Congress \& Exposition (1995).

Farajollahi, B., Etemad, S.G., Hojjat, M. Heat transfer of nanofluids in a shell and tube heat exchanger. Int. J. Heat Mass Transf., 53, 12-17 (2010). https:// doi.org/10.1016/j.ijheatmasstransfer.2009.10.019

Fatehi, M.R., Raeissi, S., Mowla, D. An artificial neural network to calculate pure ionic liquid densities without the need for any experimental data. J. Supercrit. Fluids, 95, 60-67 (2014). https:// doi.org/10.1016/j.supflu.2014.07.024

Ge, R., Hardacre, C., Nancarrow, P., Rooney, D.W. Thermal conductivities of ionic liquids over the temperature range from $293 \mathrm{~K}$ to $353 \mathrm{~K}$. J. Chem. Eng. Data, 52, 1819-1823 (2007). https://doi. org/10.1021/je700176d

Ghandi, K. A Review of Ionic Liquids, Their Limits and Applications. Green Sustain. Chem., 4, 44-53 (2014). https://doi.org/10.4236/gsc.2014.41008

Haghbakhsh, R., Adib, H., Keshavarz, P., Koolivand, M., Keshtkari, S. Development of an artificial neural network model for the prediction of hydrocarbon density at high-pressure, high temperature conditions. Thermochim. Acta, 551, 124-130 (2013). https://doi.org/10.1016/j.tca.2012.10.022

Hamidova, R., Kul, I., Safarov, J., Shahverdiyev, A., Hassel, E. Thermophysical properties of 1-butyl3-methylimidazolium bis(trifluoromethylsulfonyl) imide at High Temperatures and Pressures. Brazilian J. Chem. Eng., 32, 303-316 (2015). https://doi. org/10.1590/0104-6632.20150321s00003120

Heris, S.Z., Esfahany, M.N., Etemad, S.G. Experimental investigation of convective heat transfer of $\mathrm{Al}_{2} \mathrm{O}_{3}$ /water nanofluid in circular tube. Int. J. Heat Fluid Flow, 28, 203-210 (2007). https:// doi.org/10.1016/j.ijheatfluidflow.2006.05.001

Hezave, A.Z., Raeissi, S., Lashkarbolooki, M. Estimation of Thermal Conductivity of Ionic Liquids Using a Perceptron Neural Network. Ind. Eng. Chem. Res., 51, 9886-9893 (2012). https:// doi.org/10.1021/ie202681b

Hosseini, S.M., Alavianmehr, M.M., Moghadasi, J. Transport properties of pure and mixture of ionic liquids from new rough hard-sphere-based model. Fluid Phase Equilib., 429, 266-274 (2016). https:// doi.org/10.1016/j.fluid.2016.09.004
Kumar, S., Chakrabarti, S. A Review: Enhancement of Heat Transfer with Nanofluids. Int. J. Eng. Res. Technol., 3, 549-557 (2014).

Lashkarbolooki, M., Hezave, A.Z., Babapoor, A. Correlation of density for binary mixtures of methanol+ionic liquids using back propagation artificial neural network. Korean J. Chem. Eng., 30, 213-220 (2013). https://doi.org/10.1007/s11814012-0112-2

Lazzús, J.A. Estimation of the thermal conductivity $\lambda(\mathrm{T}, \mathrm{P})$ of ionic liquids using a neural network optimized with genetic algorithms. Comptes Rendus Chim., 19, 333-341 (2015a). https://doi. org/10.1016/j.crci.2015.09.010

Lazzús, J.A. A group contribution method to predict the thermal conductivity $\lambda(\mathrm{T}, \mathrm{P})$ of ionic liquids. Fluid Phase Equilib., 405, 141-149 (2015b). https:// doi.org/10.1016/j.fluid.2015.07.015

Lazzús, J.A., Pulgar-Villarroel, G. Estimation of thermal conductivity of ionic liquids using quantitative structure-property relationship calculations. J. Mol. Liq., 211, 981-985 (2015). https://doi.org/10.1016/j.molliq.2015.08.037

Lee, J., Mudawar, I. Assessment of the effectiveness of nanofluids for single-phase and two-phase heat transfer in micro-channels. Int. J. Heat Mass Transf., 50, 452-463 (2007). https://doi.org/10.1016/j. ijheatmasstransfer.2006.08.001

Li, Q., Xuan, Y. Heat Transfer Enhancement of Nanofluids. Int. J. Heat Mass Transf., 21, 5864 (2000). https://doi.org/10.1016/S0142727X(99)00067-3

Li, W., Zou, C. Experimental investigation of stability and thermo-physical properties of functionalized $\beta-\mathrm{CD}-\mathrm{TiO}_{2}-\mathrm{Ag}$ nanofluids for antifreeze. Powder Technol., 340, 290-298 (2018a). https://doi. org/10.1016/j.powtec.2018.09.005

Li, W., Zou, C. Deep desulfurization of gasoline by synergistic effect of functionalized $\beta-\mathrm{CD}-\mathrm{TiO}_{2}-\mathrm{Ag}$ nanoparticles with ionic liquid. Fuel, 227, 141-149 (2018b). https://doi.org/10.1016/j.fuel.2018.04.083

Li, W., Zou, C., Li, X. Thermo-physical properties of cooling water-based nanofluids containing $\mathrm{TiO}_{2}$ nanoparticles modified by Ag elementary substance for crystallizer cooling system. Powder Technol., 329, 434-444 (2018). https://doi.org/10.1016/j. powtec.2018.01.089

Li, W., Zou, C., Li, X. Thermo-physical properties of waste cooking oil-based nanofluids. Appl. Therm. Eng., 112, 784-792 (2017). https://doi. org/10.1016/j.applthermaleng.2016.10.136

Ma, M., Zou, C. Effect of nanoparticles on the mass transfer process of removal of hydrogen sulfide in biogas by MDEA. Int. J. Heat Mass Transf., 127, 385-392 (2018). https://doi.org/10.1016/j. ijheatmasstransfer.2018.06.091 
Ma, Q., Zhang, H., Guo, R., Cui, Y., Deng, X., Cheng, X., Xie, M., Cheng, Q., Li, B. A novel strategy to fabricate plasmonic $\mathrm{Ag} / \mathrm{AgBr}$ nano-particle and its enhanced visible photocatalytic performance and mechanism for degradation of acetaminophen. J. Taiwan Inst. Chem. Eng., 80, 176-183 (2017). https://doi.org/10.1016/j.jtice.2017.06.033

Najafi-Marghmaleki, A., Khosravi-Nikou, M.R., Barati-Harooni, A. A new model for prediction of binary mixture of ionic liquids+water density using artificial neural network. J. Mol. Liq., 220, 232-237 (2016). https://doi.org/10.1016/j. molliq.2016.04.085

Perarasu, T., Arivazhagan, M., Sivashanmugam, P. Experimental and CFD heat transfer studies of $\mathrm{Al}_{2} \mathrm{O}_{3}$-water nanofluid in a coiled agitated vessel equipped with propeller. Chinese J. Chem. Eng., 21, 1232-1243 (2013). https://doi.org/10.1016/ S1004-9541(13)60579-0

Piriyawong, V., Thongpool, V., Asanithi, P., Limsuwan, P. Preparation and characterization of alumina nanoparticles in deionized water using laser ablation technique. J. Nanomater., 2012, 1-6 (2012). https://doi.org/10.1155/2012/819403

Santos, D., Góes, M., Franceschi, E., Santos, A., Dariva, C., Fortuny, M., Mattedi, S. Phase equilibria for binary systems containing ionic liquid with water or hydrocarbons. Braz. J. Chem. Eng., 32, 967-974 (2015). https://doi.org/10.1590/0104$6632.20150324 \mathrm{~s} 00003609$
Sathyabhama, A. and Hegde, R.N., Thermal Applications of Ionic Liquids - A Review, in: Trends and Advances in Mechanical Engineering, 1-7 (2006).

Shojaee, S.A., Farzam, S., Hezave, A.Z., Lashkarbolooki, M., Ayatollahi, S., A new correlation for estimating thermal conductivity of pure ionic liquids. Fluid Phase Equilib., 354, 199-206 (2013). https://doi.org/10.1016/j. fluid.2013.06.004

Soman, D.P., Kalaichelvi, P., Radhakrishnan, T.K. Review on Suitability of Ionic Liquids for Heat Transfer Applications. Emerg. Trends Chem. Eng., 3, 40-51 (2016).

Uvarov, V., Popov, I. Metrological characterization of X-ray diffraction methods for determination of crystallite size in nano-scale materials. Mater. Charact., 58, 883-891 (2007). https://doi. org/10.1016/j.matchar.2006.09.002

Valkenburg, M.E.V., Vaughn, R.L., Williams, M., Wilkes, J.S. Thermochemistry of ionic liquid heattransfer fluids. Thermochim. Acta, 425, 181-188 (2005). https://doi.org/10.1016/j.tca.2004.11.013

Vasheghani, M., Marzbanrad, E., Zamani, C., Aminy, M., Raissi, B., Ebadzadeh, T., Barzegar-Bafrooei, $\mathrm{H}$. Effect of $\mathrm{Al}_{2} \mathrm{O}_{3}$ phases on the enhancement of thermal conductivity and viscosity of nanofluids in engine oil, Heat Mass Transf., 47, 1401-1405 (2011). https://doi.org/10.1007/s00231-0110806-8 